\title{
VII. The determination of a constant in capillarity
}

\section{R.D. Kleeman D.Sc. B.A.}

To cite this article: R.D. Kleeman D.Sc. B.A. (1909) VII. The determination of a constant in capillarity, Philosophical Magazine Series 6, 18:103, 39-44, DOI: $10.1080 / 14786440708636672$

To link to this article: http://dx.doi.org/10.1080/14786440708636672

$$
\text { 册 Published online: } 21 \text { Apr } 2009 .
$$

6 Submit your article to this journal $\pi$

LII Article views: 3

Q View related articles $\asymp$ 
VII. The Determination of a Constant in Capillarity. By R. D. Klemman, D.Se., B.A., Research Student of Emmanuel College, Cambridge*.

WHEN the area of the surface of a liquid is increased the increase in the amount of energy in the surfacefilm of the liquid is equal to the sum of the external work done and the amount of heat absorbed from the surrounding bodies to keep the temperature constant during the process. The relation between these quantities can be immediately obtained by means of Helmholtz's free energy equation connecting the total energy with the free energy, which gives

$$
\mathrm{E}+\mathrm{T} \frac{d \lambda}{d \mathrm{~T}^{\mathrm{T}}}=\lambda, \quad \cdot \quad \cdot \quad \cdot \quad \cdot
$$

where $\lambda$ denotes the surface-tension and $E$ the total energy corresponding to the temperature T. $\lambda$ is equal to the external work done, and $-\mathrm{T} \frac{d \lambda}{d \mathrm{~T}}$ is therefore equal to the amount of heat absorbed from the surrounding bodies. This formula was first given by Lord Kelvin.

Whittaker + has calculated the values of $\mathrm{E}$, the total energy for different temperatures, for a number of liquids, using the surface-tension determinations of Ramsay and Shields ${ }_{+}^{+}$. $\mathrm{He}$ found that the energy $\mathrm{E}$ per $\mathrm{cm}^{2}$ of the film of a liquid is proportional to the product of the internal latent heat of evaporation into the absolute temperature of the liquid, or

$$
\mathrm{E}=\mathrm{KTL}, \cdot \cdot \cdot \cdot \cdot \cdot \cdot
$$

where $L$ is the internal latent heat of evaporation corresponding to the temperature $\mathrm{T}$, and $\mathrm{K}$ is a constant. The constant $K$ was found to be different for the various liquids. The extent of the agreement of this empirical law with the experimental facts is shown by the following tables taken from Whittaker's paper.

\footnotetext{
* Communicated by the Author.

+ Proc. Roy. Soc. A. vol. Ixxxi. p. 21 (1908).

I Phil. Trans. A. vol. clxxxiv. p. 647 (1893).
} 
Ether.

\begin{tabular}{|c|c|c|c|}
\hline 'I'. & Ii. & L. & $\begin{array}{l}\frac{\mathrm{E} \times 10^{4}}{\mathrm{TL}} \\
\text { or } \\
\mathrm{K} 10^{4} .\end{array}$ \\
\hline 313 & $49 \cdot 1$ & $75 \cdot 36$ & $20 \cdot 8$ \\
\hline 323 & 489 & 73.01 & $20 \cdot 8$ \\
\hline 333 & $48-9$ & 7079 & 20.5 \\
\hline 343 & 47.8 & 6835 & $20 \cdot 4$ \\
\hline 353 & $47 \cdot 1$ & 65.85 & 203 \\
\hline 363 & $46 \cdot 1$ & 63.31 & $20 \cdot 1$ \\
\hline 373 & $45 \cdot 5$ & $60 \cdot 33$ & $20 \cdot 2$ \\
\hline 383 & $44 \cdot 7$ & 5807 & $20 \cdot 1$ \\
\hline 398 & $43 \cdot 8$ & $54 \cdot 9]$ & $20 \cdot 3$ \\
\hline 403 & $42 \cdot 6$ & $51 \cdot 62$ & $20 \cdot 5$ \\
\hline 413 & $4 l \cdot 1$ & $48 \cdot 31$ & 206 \\
\hline 423 & $39 \cdot 3$ & $44 \cdot 38$ & $20 \cdot 9$ \\
\hline
\end{tabular}

Benzene.

\begin{tabular}{|c|c|c|c|}
\hline T. & E. & L. & $\begin{array}{c}\text { E } \times 10^{-4} \\
\text { LT } \\
\text { or } \\
\text { K104. }\end{array}$ \\
\hline 353 & $59 \cdot 5$ & $85 \cdot 6$ & $19 \cdot 7$ \\
363 & $60 \cdot 2$ & $83 \cdot 7$ & $19 \cdot 8$ \\
373 & $60 \cdot 9$ & $82 \cdot 0$ & $19 \cdot 9$ \\
383 & $61 \cdot 1$ & $50 \cdot 0$ & $20 \cdot 0$ \\
393 & $60 \cdot 7$ & $78 \cdot 1$ & $19 \cdot 8$ \\
403 & $60 \cdot 1$ & $76 \cdot 1$ & $19 \cdot 3$ \\
413 & $59 \cdot 4$ & $74 \cdot 1$ & $19 \cdot 4$ \\
423 & $58 \cdot 8$ & $71 \cdot 9$ & $19 \cdot 3$ \\
433 & $58 \cdot 0$ & $69 \cdot 7$ & $19 \cdot 2$ \\
443 & $57 \cdot 2$ & $67 \cdot 5$ & $19 \cdot 1$ \\
453 & $56 \cdot 1$ & $65 \cdot 1$ & $19 \cdot 0$ \\
463 & $55 \cdot 0$ & 62.7 & $19 \cdot 0$ \\
473 & $54 \cdot 0$ & $59 \cdot 9$ & $19 \cdot 1$ \\
483 & $52 \cdot 9$ & $57 \cdot 0$ & $19 \cdot 3$ \\
493 & $51 \cdot 5$ & $53 \cdot 8$ & $19 \cdot 4$ \\
503 & $49 \cdot 9$ & $50 \cdot 5$ & $19 \cdot 7$ \\
513 & $48 \cdot 1$ & $46 \cdot 6$ & $19 \cdot 1$ \\
\hline & & & \\
\hline
\end{tabular}

Methyl formate.

\begin{tabular}{|c|c|c|c|}
\hline 'T. & E. & L. & $\begin{array}{c}\frac{\mathrm{E} \times 10^{4}}{\mathrm{I} L} \\
\text { or } \\
\mathrm{K} 10^{4} .\end{array}$ \\
\hline 303 & $69 \cdot 4$ & $107 \cdot 49$ & $21 \cdot 3$ \\
\hline 313 & 68.8 & 103.95 & $21 \cdot 1$ \\
\hline 323 & $68 \cdot 2$ & 99.51 & $21 \cdot 2$ \\
\hline 333 & $67 \cdot 5$ & $95 \cdot 59$ & $21 \%$ \\
\hline 343 & $67 \cdot 3$ & $92 \cdot 16$ & 213 \\
\hline 353 & $66 \cdot 2$ & $88 \cdot 03$ & $1 \cdot 3$ \\
\hline 363 & $65 \cdot 5$ & $85 \cdot 10$ & $21 \%$ \\
\hline 3783 & $64 \cdot 6$ & $82 \cdot 43$ & 210 \\
\hline 383 & $63 \cdot 8$ & $79 \cdot 21$ & 21.0 \\
\hline 398 & 629 & $75 \cdot 92$ & $21 \cdot 1$ \\
\hline 403 & $61 \cdot 8$ & 71.95 & $21 \cdot 3$ \\
\hline 413 & $60 \cdot 4$ & $68 \cdot 10$ & 21.5 \\
\hline 423 & $58 \cdot 8$ & 64.03 & $21 \cdot 7$ \\
\hline
\end{tabular}

Carbon tetrachloride.

\begin{tabular}{|c|c|c|c|}
\hline 'I. & E. & L. & $\frac{\mathrm{E} \times 10}{\mathrm{~L} T}$ \\
\hline 363 & 57.9 & $40 \cdot 62$ & $39 \cdot 3$ \\
\hline 373 & $57 \cdot 5$ & $39 \cdot 68$ & 38.9 \\
\hline 383 & 568 & 38.64 & $38 \cdot 4$ \\
\hline 393 & 564 & $37 \cdot 63$ & $38 \cdot 2$ \\
\hline 403 & $55 \cdot 6$ & 36.58 & $37 \cdot 7$ \\
\hline 413 & $54 \cdot 8$ & $35 \cdot 56$ & $37 \cdot 3$ \\
\hline 423 & 539 & 34.42 & $37 \cdot 0$ \\
\hline 433 & $53 \cdot 1$ & 3328 & 37.9 \\
\hline 443 & $52 \cdot 6$ & 32.07 & 37.0 \\
\hline 453 & $52 \cdot 2$ & 30.83 & $37 \cdot 4$ \\
\hline 463 & $51 \cdot 7$ & $29 \cdot 52$ & $37 \cdot 8$ \\
\hline 473 & $50 \cdot 8$ & $28 \cdot 22$ & $37 \cdot 1$ \\
\hline 483 & $50 \cdot 3$ & 26.83 & $37 \cdot 8$ \\
\hline 493 & $49 \cdot 8$ & 25.35 & $37 \cdot 8$ \\
\hline 503 & $47 \cdot 3$ & 2373 & $37 \cdot 6$ \\
\hline
\end{tabular}

The object of this paper is to find a value for $\mathrm{K}$ of a liquid in terms of its absolute constants. Such a determination is evidently desirable.

Ramsay, following Eötvos, has shown that the surfacetension of a liquid at the absolute temperature $T$ is connected with the absolute temperature and other quantities by 
Chloro-benzene.

\begin{tabular}{|c|c|c|c|}
\hline T. & E. & I. & $\begin{array}{c}\mathrm{E} \times 10 \\
\mathrm{TL} \\
\text { or } \\
\mathrm{K} 10^{4} .\end{array}$ \\
\hline 423 & $59 \cdot 8$ & $65 \cdot 81$ & $21 \cdot 4$ \\
\hline 433 & $59 \cdot 9$ & $64 \cdot 12$ & $21 \cdot 6$ \\
\hline 443 & $60^{\circ} 0$ & 63.02 & 21.5 \\
\hline 453 & 600 & 61.46 & 21.5 \\
\hline 463 & $59-3$ & $59 \cdot 97$ & $21 \cdot 3$ \\
\hline 473 & $58 \cdot 6$ & $58 \cdot 31$ & $21 \cdot 3$ \\
\hline 483 & $58 \cdot 1$ & 5681 & $21 \cdot 2$ \\
\hline 493 & $57 \cdot 4$ & $55 \cdot 29$ & $21 \cdot 1$ \\
\hline 503 & 567 & 5383 & 209 \\
\hline 513 & 559 & 5243 & 208 \\
\hline 523 & $55 \cdot 1$ & 5081 & $20 \cdot 7$ \\
\hline 533 & $53 \cdot 8$ & $49 \cdot 09$ & $20 \cdot 6$ \\
\hline
\end{tabular}

the equation

$$
\lambda v^{2 / 3}=\mathrm{A}\left(\mathrm{T}_{c}-\mathrm{T}-a\right)
$$

where $v$ denotes the molecular volume of the liquid, and A is a constant which is practically the same for all liquids, being equal to about $2 \cdot 1, \mathrm{~T}_{c}$ is the critical temperature, and $a$ is another constant which is also approximately the same for all liquids, its mean value being about 5 . Substituting for $\lambda$ in equation (1) by means of equation (3), we obtain

$$
\mathrm{E}=\mathrm{A} \frac{\left(\mathrm{T}_{\mathrm{c}}-\mathrm{T}-a\right)}{r^{2 / 3}}+\frac{\mathrm{AT}}{v^{2 / 3}}+\frac{2}{3} \mathrm{TA} \frac{\left(\mathrm{T}_{\mathrm{c}}-\mathrm{T}-a\right)}{v^{5 / 3}} \frac{d v}{d \mathrm{~T}} .
$$

Let us suppose that $\lambda$ refers to a temperature much below the critical temperature of the liquid, say near the absolnte zero. The value of $\frac{d v}{d \mathrm{~T}}$ is then a very small fraction, and $\mathrm{T}\left(\mathrm{T}_{c}-\mathrm{T}-\alpha\right)$ small in comparison with $\left(\mathrm{T}_{c}-\mathrm{T}-a\right)$. The third term on the right-band side of the last equation may at low temperatures be, therefore, neglected in comparison with the other terms, and in that case

$$
\mathrm{E}=\frac{\mathrm{A}}{v^{2 / 3}}\left(\mathrm{~T}_{c}-a\right) \text {. }
$$

The molecular volume is given by $v=\frac{m}{\rho}$, where $m$ is the molecular weight and $\rho$ the density of the liquid. Sulbstituting for $v$ in the last equation we have

$$
\mathrm{E}=\frac{\rho^{2 / 3} \mathrm{~A}\left(\mathrm{~T}_{c}-\alpha\right)}{m^{2 / 3}}
$$


And since $\mathrm{E}=\mathrm{KLT}$, we have

$$
\mathrm{K}=\frac{\rho^{2 / 3} \mathrm{~A}}{m^{2 / 3} \mathrm{LT}}\left(\mathrm{T}_{\tau}-\alpha\right) . \quad . \quad . \quad . \quad .
$$

The latent heat of evaporation $\mathrm{L}_{1}$ of a liquid is given by the well-known thermodynamical relation

$$
\mathrm{L}_{1}=\left(v_{1}-v_{2}\right) \mathrm{T} \frac{d p}{d T},
$$

where $v_{1}$ and $v_{2}$ denote respectively the volumes of a gram of the saturated vapour and the liquid, and $p$ denotes the pressure. For temperatures well removed from the critical temperature the vapour behaves approximately as a perfect gas, and this equation may then be written

$$
\mathrm{I}_{1}=\frac{\mathrm{RT}^{2}}{m p} \frac{d p}{d^{\prime} \mathrm{T}}
$$

where $\mathbf{R}$ denotes the gas constant. If the equation be written in the form

$$
\frac{\mathrm{L}_{1} m}{\mathrm{~T}}=\frac{\mathrm{RT}}{p} \frac{d p}{d \mathrm{~T}}
$$

and the temperatures and pressures at the right-hand side be expressed in terms of the critical temperature and pressure, we obtain

$$
\frac{\mathrm{L}_{1} m}{\mathrm{~T}}=\frac{\mathrm{R}_{\alpha} \mathrm{T}_{c}}{\beta p_{c}} \frac{p_{c}}{\mathrm{~T}_{\mathrm{c}}} \frac{d \beta}{d \alpha}=\frac{\mathrm{R} \alpha}{\beta} \frac{d \beta}{d \alpha},
$$

where $\alpha \mathrm{T}_{c}=\mathrm{T}$, and $\beta p_{c}=p$. Thus the relation between $\mathrm{L}_{1}$, $\mathrm{T}$, and $m$ for different liquids at corresponding states is given by $\frac{\mathrm{L}_{1} m}{\mathrm{~T}}=$ constant. Since the temperatures of liquids at their boiling-points are approximately corresponding temperatures, this relation holds approximately for liquids at their boiling-points; it is known in this form as Trouton's law. If the temperature of evaporation is so far removed from the critical temperature that the vapour behaves approximately as a pertect gas, the external work of evaporation $p\left(v_{1}-v_{2}\right)$ is approximately equal to $\frac{\mathrm{RT}}{m}$. Therefore

$$
\mathrm{L}+p\left(v_{1}-v_{2}\right)=\mathrm{L}+\frac{\mathrm{RT}}{m}=\mathrm{L}_{1}
$$

and therefore $\frac{\mathrm{L}_{1} m}{\mathrm{~T}}=\frac{\mathrm{L} m}{\mathrm{~T}}+\mathrm{R}=$ constant, or $\frac{\mathrm{L} m}{\mathrm{~T}}$ is also 
constant for different liquids at corresponding states. Writing $\frac{\mathrm{L} m}{\mathrm{~T}}=\mathrm{B}$, where $\mathrm{B}=\frac{\mathrm{R} \alpha}{\beta} \frac{d \beta}{d \alpha}-\mathrm{R}$, and substituting for $\mathrm{L}$ in equation (4) we obtain

$$
\mathrm{K}=\frac{\rho^{3 / 3} \mathrm{~A}\left(\mathrm{~T}_{c}-a\right) m^{1 / 3}}{\mathrm{~T}^{2} \mathrm{~B}},
$$

Expressing $\rho$ and $T$ in terms of the critical density and temperature, we obtain

$$
\mathrm{K}=\frac{\mathrm{A} \gamma^{2 / 3} \rho_{c}^{2 / 3}\left(\mathrm{~T}_{c}-a\right) m^{1 / 3}}{\mathrm{~B} \alpha^{2} \mathrm{~T}_{c}^{\mathrm{\gamma}}},
$$

where $\rho=\gamma \rho_{c}$.

Let us write the equation in the form

$$
\mathrm{K}=\frac{\mathrm{M} m^{1 / 3}\left(\mathrm{~T}_{\mathrm{c}}-a\right) \rho_{\mathrm{e}}^{2 / 3}}{\mathrm{I}_{c}^{2}},
$$

where $\mathrm{M}=\frac{\mathrm{A}}{\overline{\mathrm{B}}} \frac{\gamma^{2 / 3}}{\alpha^{2}}$. Now it is known that $\mathrm{K}$ is a constant for a given liquid, therefore $M$ must be a constant for the liquid. Further, in obtaining $\mathrm{K}$ for different liquids we may suppose the liquids taken at corresponding states, so that the values of $\alpha, \beta, \gamma$, are the same for each liquid. Then it follows that since $M$ is a function of $\alpha, \beta$, and $\gamma$ only, it must be the same for each liquid.

Further, since $a$ is equal to about 5 and $\mathrm{T}_{c}$ of the order $500, \frac{a}{T_{c}^{2}}$ may be neglected in comparison with $\frac{1}{\mathrm{~T}_{c}^{2}}$. We bave then, finally,

$$
\mathrm{K}=\frac{\mathrm{M} m^{1 / 3} \rho_{c}{ }^{2 / 3}}{\mathrm{~T}_{c}}, \ldots . .
$$

where $\mathrm{M}$ is a constant which is the same for every liquid.

The following table contains the values of $10^{4} \frac{\mathrm{M} m^{1 / 3} \rho_{c}^{2 / 3}}{\mathrm{~T}_{c}}$ for a few liquids calculated from the data given in the second, third, and fourth columns of the table, the value of $M$ being put equal to $5.57 \times 10^{-1}$ in each case. The values of $10^{4} \mathrm{~K}$, contained in the fitth column of the table, are the means of the values contained in the preceding tables. It will be seen that the values of $\mathrm{K}$ given by equation (5) agree fairly well with the values given by the equation $K=\frac{E}{\overline{L T} \text {. }}$. A better agreement can scarcely be expected since the critical constants cannot be determined with any great accuracy. 


\begin{tabular}{|c|c|c|c|c|c|}
\hline \multicolumn{6}{|c|}{$\mathrm{M}=5.57 \times 10-\mathrm{I}$} \\
\hline & $\mathrm{T}_{c}$ & $\rho_{c}$, & $m$. & $\mathrm{K} 10^{4}$ & $\frac{10^{4} \mathrm{M} m^{1 / 3} \rho_{c}^{2 / 3}}{\mathrm{~T}_{c}}$ \\
\hline Ether & $466 \cdot 6$ & 2604 & 74 & $20 \cdot 5$ & $20 \cdot 4$ \\
\hline Methyl formate & 487 & 3489 & 60 & $21 \cdot 2$ & $22 \cdot 2$ \\
\hline Carbon tetrachloride & 556 & 5576 & $153 \cdot 8$ & $38 \cdot 1$ & $36 \cdot 4$ \\
\hline Benzene ... & $561 \cdot 5$ & 3045 & $78 \cdot 05$ & $19 \cdot 5$ & $19 \cdot 2$ \\
\hline Chloro-benzene ... & 633 & 3654 & $112: 5$ & $21 \cdot 2$ & $21 \cdot 7$ \\
\hline
\end{tabular}

The value of $\mathrm{K}$ given by equation (4) will not apply to polymerized liquids because the value of $A$ is then not a constant, but varies with the nature of the liquid and its temperature. It is also very probable that the relation given by Whittaker does not apply to such liquids.

If the critical density and temperature of a liquid is known, and its capillary constants for temperatures differing by a small interval, the internal latent heat can be calculated for these temperatures by the equation

$$
\mathrm{I}_{1}=\left(\frac{\lambda}{\mathrm{T}}-\frac{d \lambda}{d \overline{\mathrm{T}}}\right) \frac{\mathrm{T}_{\mathrm{c}}}{m^{1 / 3} \rho_{c}^{2 / 3}} \frac{1}{5 \cdot 57 \times 10^{-1}}
$$

deduced from the equations (1), (2), and (5). An inspection of Whittaker's results shows that $K$ or $\frac{E}{L T}$ is very constant for different temperatures, and this equation would therefore give fairly accurate results.

If a large number of determinations of $\lambda$ for different temperatures are not arailable, the values of $\lambda$ and $\frac{d \lambda}{d \mathrm{~T}}$ in the above equation may be obtained from equation (2), the constants in the equation having first been determined by means of the values of $\lambda$ for two different temperatures. This, however, will not give very accurate values for $L$.

Equation (5), by writing it in the form

$$
\frac{\mathrm{E}}{\mathrm{L} \mathbf{I}^{\mathrm{T}}}=\frac{\mathrm{M} m^{1 / 3} \rho_{c}{ }^{2 / 3}}{\mathrm{~T}_{c}}
$$

may be used to find either of the critical constants it contains if one of them is known. The right-hand side may be evaluated for any convenient temperature.

Cambridge, March 20, 1909. 